\title{
Thickness Dependent on Photocatalytic Activity of Hematite Thin Films
}

\author{
Yen-Hua Chen and Kuo-Jui Tu \\ Department of Earth Sciences, National Cheng Kung University, No. 1, University Road, Tainan 701, Taiwan \\ Correspondence should be addressed to Yen-Hua Chen, yhc513@mail.ncku.edu.tw
}

Received 13 July 2011; Accepted 16 September 2011

Academic Editor: Shifu Chen

Copyright (๑) 2012 Y.-H. Chen and K.-J. Tu. This is an open access article distributed under the Creative Commons Attribution License, which permits unrestricted use, distribution, and reproduction in any medium, provided the original work is properly cited.

\begin{abstract}
Hematite $\left(\mathrm{Fe}_{2} \mathrm{O}_{3}\right)$ thin films with different thicknesses are fabricated by the rf magnetron sputtering deposition. The effects of film thicknesses on the photocatalytic activity of hematite films have been investigated. Hematite films possess a polycrystalline hexagonal structure, and the band gap decreases with an increase of film thickness. Moreover, all hematite films exhibit good photocatalytic ability under visible-light irradiation; the photocatalytic activity of hematite films increases with the increasing film thickness. This is because the hematite film with a thicker thickness has a rougher surface, providing more reaction sites for photocatalysis. Another reason is a lower band gap of a hematite film would generate more electron-hole pairs under visible-light illumination to enhance photocatalytic efficiency. Experimental data are well fitted with Langmuir-Hinshelwood kinetic model. The photocatalytic rate constant of hematite films ranges from 0.052 to $0.068 \mathrm{~min}^{-1}$. This suggests that the hematite film is a superior photocatalyst under visible-light irradiation.
\end{abstract}

\section{Introduction}

Many industrial dyes are toxic and carcinogenic $[1,2]$. The organic dyes present in industrial wastewater often pose significant threats against human health and environmental pollution control. Therefore, it is important to remove organic dyes from wastewater. However, wastewater exhibits stable behavior under harsh conditions and resists biodegradation, making it difficult to remove organic dyes easily. Many wastewater treatment methods have been explored [3, $4]$, and the most commonly reported technique is the adsorption technique $[5,6]$. However, this method is now becoming unpopular because it is expensive, and the adsorbent has low recyclability [7-9].

Photocatalysis is an environment friendly process that utilizes irradiation energy for catalytic reactions. Hence, photocatalytic technology has been widely investigated for applications to the decomposition of pollutants [10-12]. The photocatalytic decomposition of wastewater is a process that combines heterogeneous catalysis with solar technologies [13]. Researchers are especially interested in developing photocatalysts that can extend the absorption wavelength into the visible-light region [14-16].
Hematites $\left(\mathrm{Fe}_{2} \mathrm{O}_{3}\right)$ are minerals belonging to the group of iron-oxide minerals; they have a hexagonal structure and exhibit paramagnetic behavior. Moreover, they show strong catalytic activity, widely and easily available, and are extremely environment friendly. In particular, hematite may be a promising candidate for visible-light photocatalysis-it can absorb visible light, collect up to $45 \%$ of solar-spectrum energy, and is one of the cheapest semiconductor materials available.

Photocatalysts are usually in the form of powders and thin films. The powders have a better adsorption activity and photocatalytic efficiency than thin films because of a considerably large surface area. However, the drawback of the powders, especially nanopowders, is that they are not easy to retrieve and may be harmful to human beings. In this study, hematite thin films are employed for the removal of methylene blue (MB) dye by photocatalytic decomposition. MB is nonbiodegradable and extensively used in the industry; therefore, it is selected as the model contaminant. The photocatalytic activity for different thicknesses of hematite thin films $(1 \mathrm{H}, 2 \mathrm{H}$, and $4 \mathrm{H})$ will be evaluated, and their thickness dependence is discussed. 


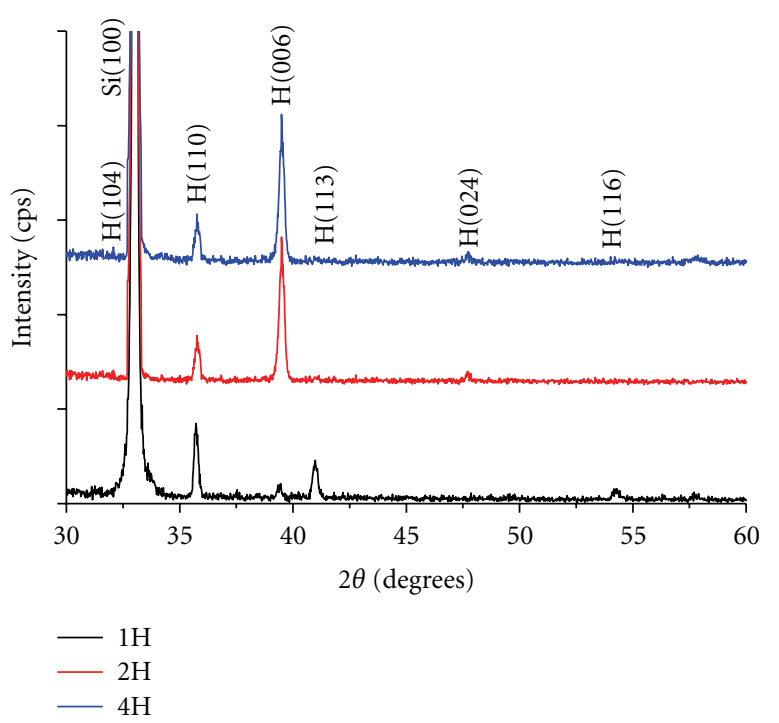

FIGURE 1: XRD patterns of hematite thin films with different deposition times.

\section{Experimental}

2.1. Preparation and Characterization of Hematite Thin Films. The hematite thin films were grown using the $\mathrm{rf}$ magnetron sputtering system on a $\mathrm{Si}(100)$ substrate. The $\mathrm{Fe}_{2} \mathrm{O}_{3}$ target was prepared as the starting material. The deposition was carried out at $600^{\circ} \mathrm{C}$ in the atmosphere having an $\mathrm{Ar} / \mathrm{O}_{2}$ ratio of 14/6, at a total pressure of 20 mtorr. Several deposition times of the $\mathrm{Fe}_{2} \mathrm{O}_{3}$ films were studied: 1.0, 2.0, and $4.0 \mathrm{hr}$, which were in different thicknesses. The crystal structure of $\mathrm{Fe}_{2} \mathrm{O}_{3}$ thin films was characterized by X-ray powder diffraction (XRD). The morphology and the grain size of $\mathrm{Fe}_{2} \mathrm{O}_{3}$ films were observed by a field-emission scanning electron microscope (FE-SEM). Magnetic properties of $\mathrm{Fe}_{2} \mathrm{O}_{3}$ films were measured by a superconducting quantum interference device (SQUID) magnetometer at room temperature within a magnetic field up to $1 \mathrm{~T}$. The band gap of the specimens was examined via a UV-Vis diffuse reflectance spectrometer.

2.2. Photocatalytic Experiment. In the photocatalytic experiment, the degradation of $\mathrm{MB}\left(\mathrm{C}_{16} \mathrm{H}_{18} \mathrm{ClN}_{3} \mathrm{~S} \bullet 3 \mathrm{H}_{2} \mathrm{O}\right)$ was measured under visible-light irradiation (wavelength $>400 \mathrm{~nm}$ ) in a black box. The power of the visible light was $500 \mathrm{~W}$. The visible-light lamp was placed vertically on the closed reaction vessel at a distance of $60 \mathrm{~cm}$. The reaction system was kept at $25^{\circ} \mathrm{C}$ with cooling water. The initial concentration of $\mathrm{MB}$ was adjusted to $1.0 \mathrm{ppm}(100 \mathrm{~mL})$, and then, $1 \mathrm{~cm} \times 1 \mathrm{~cm}$ of the $\mathrm{Fe}_{2} \mathrm{O}_{3}$ thin film (photocatalyst) was added. After every measurement, the MB solution was centrifuged and filtered, and subsequently, the $2 \mathrm{~mL} \mathrm{MB}$ solution was removed for concentration measurements. The variations in the MB concentration were measured using a UV-Vis spectrometer (UV-Vis).

2.3. Photocatalytic Model. The kinetic mechanism is important because it describes the removal rate of the photocatalyst and controls the residual time of the entire process. The

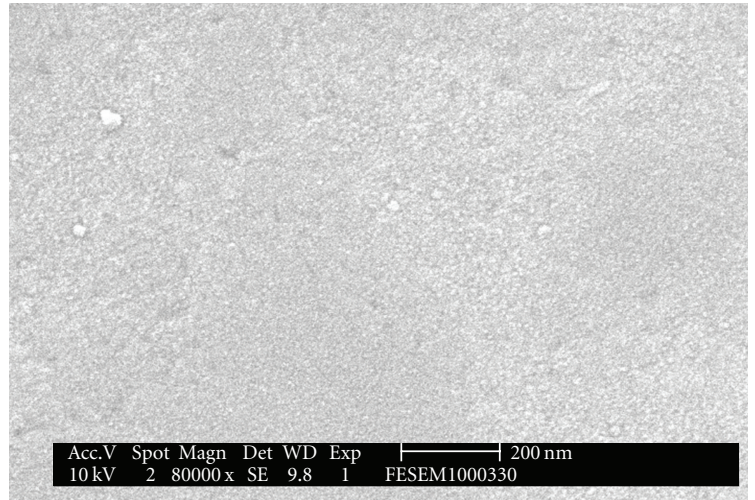

(a)

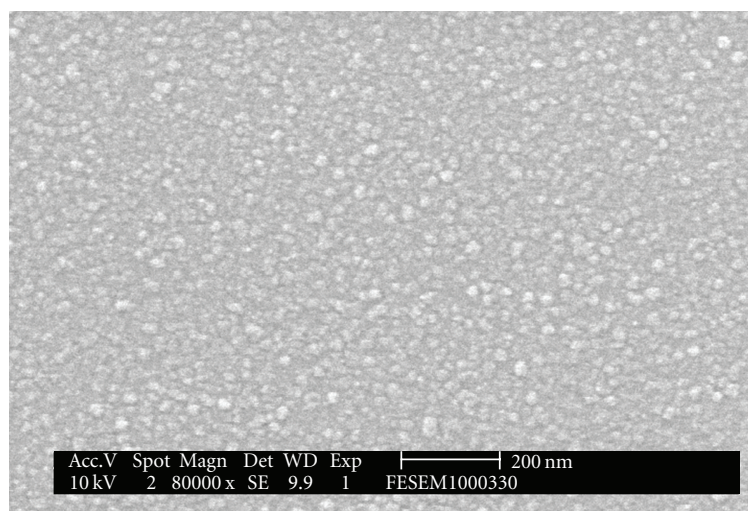

(b)

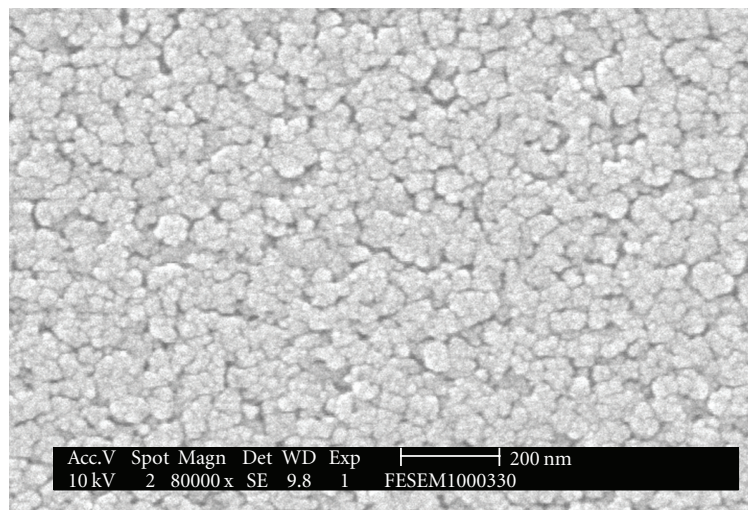

(c)

Figure 2: Plane view of FE-SEM images of hematite thin films with various deposition times: (a) $1.0 \mathrm{hr}$, (b) $2.0 \mathrm{hr}$, and (c) $4.0 \mathrm{hr}$.

heterogeneous photocatalysis usually follows a pseudo-firstorder equation, which can be expressed by the LangmuirHinshelwood kinetic model $[17,18]$

$$
r_{\mathrm{LH}}=-\frac{d C}{d t}=k \cdot \frac{K C_{0}}{1+K C_{0}} \quad \text { or } \ln \frac{C}{C_{0}}=k^{\prime} t,
$$

where $r_{\mathrm{LH}}$ is the photocatalytic reaction rate, $C_{0}$ is the initial concentration, $C$ is the concentration at time $t, k$ is the reaction rate constant, $K$ is the equilibrium adsorption constant, and $k^{\prime}$ is the pseudo-first-order rate constant (photocatalytic rate constant). 


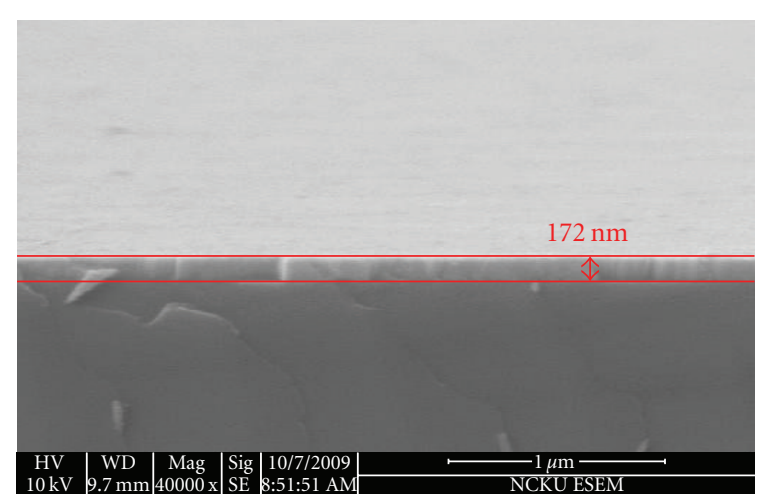

(a)

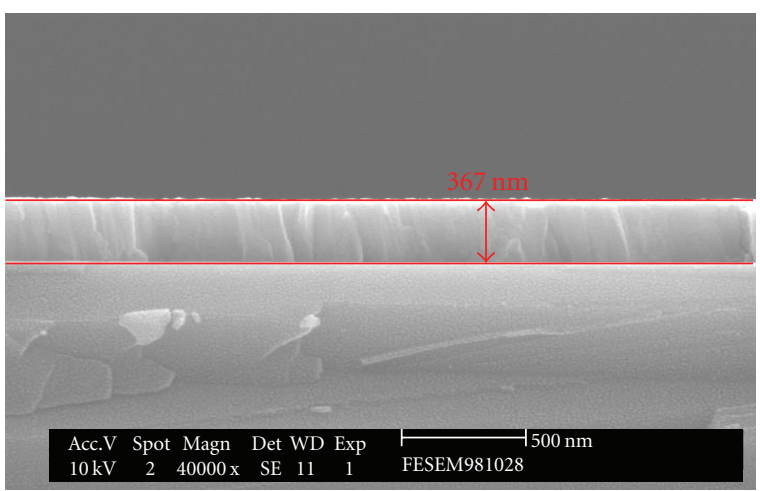

(b)

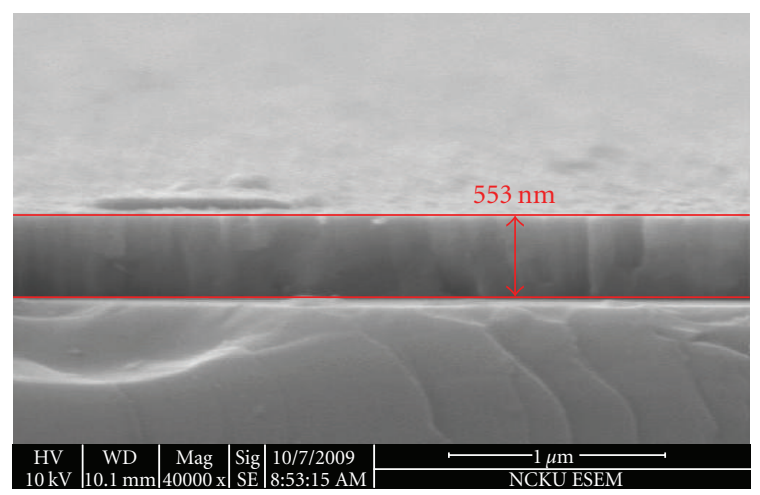

(c)

FIGURE 3: Cross-section of FE-SEM images of hematite thin films with different deposition times: (a) $1.0 \mathrm{hr}$, (b) $2.0 \mathrm{hr}$, and (c) $4.0 \mathrm{hr}$.

\section{Results and Discussion}

3.1. Characterization of Hematite Thin Films. The XRD patterns of the prepared $\mathrm{Fe}_{2} \mathrm{O}_{3}$ films are shown in Figure 1. The diffraction peaks can be identified as hematite with a hexagonal structure, which is in agreement with the standard data given in its JCPDS card (33-0664). No other impurity peaks can be detected, and the diffraction intensity increases with the increasing deposition time. Moreover, the strong and sharp diffraction peaks of the films indicate well-crystallized hematite films that can be easily obtained using the aforementioned sputtering parameters.

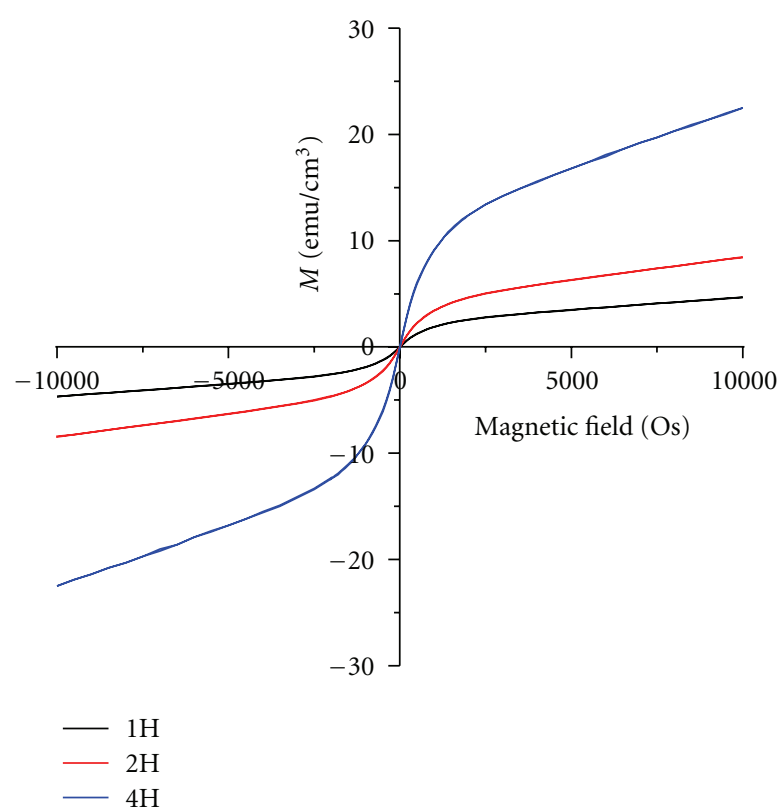

FIgURE 4: Magnetization plots as a function of magnetic field of hematite thin films with various film thicknesses.

TABLe 1: Grain size, magnetic properties, band gap, and related parameters of photocatalysis of hematite thin films with various film thicknesses.

\begin{tabular}{lccc}
\hline Properties & $1 \mathrm{H}$ & $2 \mathrm{H}$ & $4 \mathrm{H}$ \\
\hline Film thickness $(\mathrm{nm})$ & 172 & 367 & 553 \\
Particle size $(\mathrm{nm})$ & 17 & 35 & 77 \\
Band gap $(\mathrm{eV})$ & 2.77 & 2.74 & 2.71 \\
Maximal magnetization $\left(\mathrm{emu} / \mathrm{cm}^{3}\right)$ & 4.7 & 8.6 & 22.6 \\
Rate constant $(1 / \mathrm{min})$ & 0.052 & 0.055 & 0.068 \\
\hline
\end{tabular}

The film thickness, morphology, and grain size of the hematite thin films investigated by FE-SEM are shown in Figures 2 and 3. The film thickness of hematite films is 172, 367 , and $553 \mathrm{~nm}$ for the deposition time of 1.0, 2.0, and $4.0 \mathrm{hr}$, respectively. All the films have fine and irregularly shaped crystal grains, and the grain size gradually increases with an increase in the layer thickness (deposition time). The grain size of hematite films is around 17,35 , and $77 \mathrm{~nm}$, and we name these films $1 \mathrm{H}, 2 \mathrm{H}$, and $4 \mathrm{H}$, as listed in Table 1 .

The magnetization plots as a function of magnetic field, at $300 \mathrm{~K}$, are shown in Figure 4. All the three specimens exhibit superparamagnetic behavior however, the bulk magnetite is paramagnetic. The maximal magnetization increases with the increasing film thickness of hematite films, which is in agreement with the previous studies $[19,20]$. The results suggest that hematite films could be manipulated or recovered rapidly by an external magnetic field. Furthermore, the nonmagnetic impurities can be excluded during hematite films recovery.

The absorbance of the UV-Vis diffuse reflectance spectrum for hematite films is shown in Figure 5(a); the absorbance for the three samples is fairly high and within the 
TABLE 2: The comparison of photocatalytic activity for various photocatalysts.

\begin{tabular}{lccc}
\hline Photocatalyst & Material & Rate constant $\left(k^{\prime}: \mathrm{min}^{-1}\right)$ & Reference \\
\hline Nanohematite & Congo red & 0.0026 & {$[21]$} \\
$\mathrm{Fe}_{2} \mathrm{O}_{3} / \mathrm{RR}\left(20 \mathrm{mM} \mathrm{H} \mathrm{O}_{2}\right)$ & Orange II & 0.0029 & $30 \%$ \\
$\mathrm{Fe}_{2} \mathrm{O}_{3}$ thin film & MB dye & $15 \%$ & {$[22]$} \\
$\mathrm{TiO}_{2} / \mathrm{Fe}_{2} \mathrm{O}_{3}$ thin film & MB dye & $8 \%$ & {$[23]$} \\
$\alpha-\mathrm{Fe}_{2} \mathrm{O}_{3} / \mathrm{SnO}_{2}$ thin film & 2-naphthol & $0.3 \%$ & {$[24]$} \\
$\mathrm{Fe}_{2} \mathrm{O}_{3}$ nanorod thin film & Rhodamine B & $0.068 / 99 \%$ & This study \\
$\mathrm{Fe}_{2} \mathrm{O}_{3}$ thin film & MB dye & & The \\
\hline
\end{tabular}

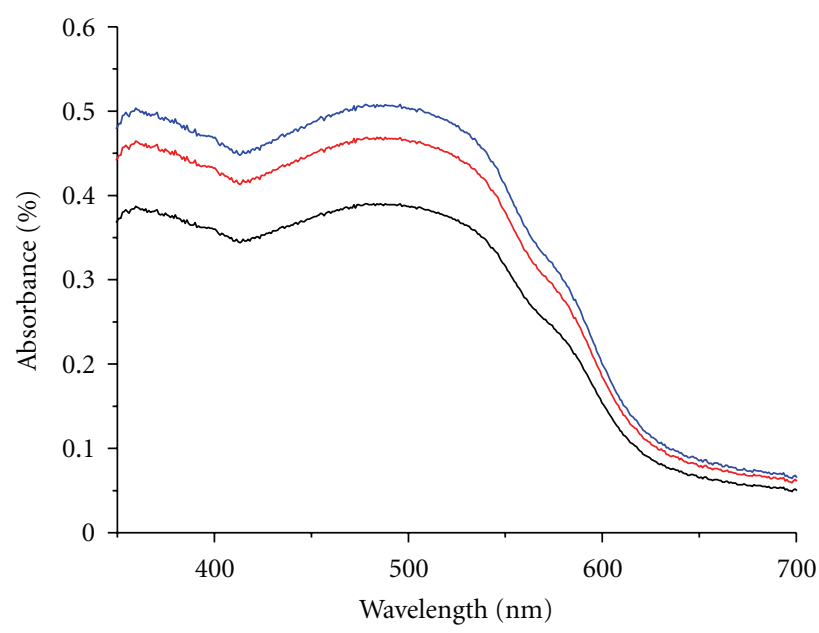

$-1 \mathrm{H}$
$-2 \mathrm{H}$
$-4 \mathrm{H}$

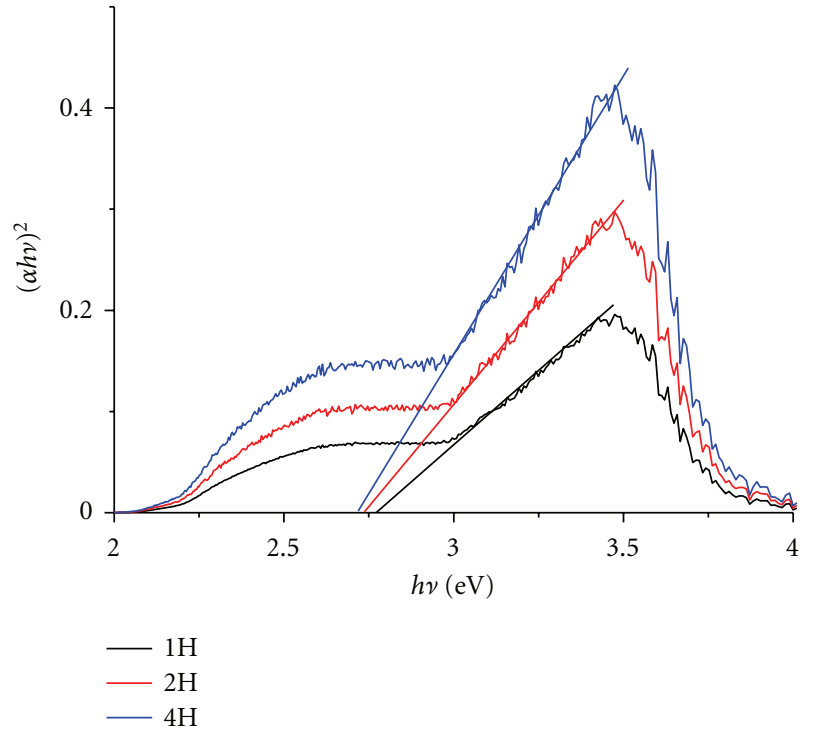

(b)

(a)

FIGURE 5: The absorbance of the (a) UV-Vis diffuse reflectance spectrum, (b) Tauc plot for hematite thin films with different film thicknesses.

region of visible-light wavelength. This result indicates that the photocatalytic properties of hematite films may exist under visible-light irradiation. By using the absorbance pattern and the following equation [21]: $\alpha h \nu=A\left(h v-E_{g}\right)^{0.5}$ (where $\alpha$ is the considered absorption coefficient, $A$ is a constant, $h$ is Planck's constant, $v$ is the photon frequency, and $E_{g}$ is the optical band gap energy), an extrapolation of the linear plot of $(\alpha h \nu)^{2}$ on the $y$-axis versus $(h v)$ on the $x$ axis gives the $E_{g}$ value. The estimate $E_{g}$ is to be approximately $2.77,2.74$, and $2.71 \mathrm{eV}$ for $1 \mathrm{H}, 2 \mathrm{H}$, and $4 \mathrm{H}$, respectively (Figure 5(b)). It is observed that the band gap of hematite films increases with a decrease of film thickness (grain size). It has been reported by Bao et al. [22] and Miller et al. [23] that the film with a small grain size would have a high potential barrier at the grain boundary; thus, it has a large band gap. An increase of the band gap with a decrease of the grain size (film thickness) is also associated with the quantum size effect, which is reported by Lee et al. [24] and Ubale et al. [25].

\subsection{Photocatalytic Activity of Hematite Thin Films}

3.2.1. Time Effect of Photocatalysis. The changes in the MB concentration as a function of time in the presence of visible light for hematite thin films $(1 \mathrm{H}, 2 \mathrm{H}$, and $4 \mathrm{H})$ are shown in Figure 6(a). The degradation efficiency is higher during the early stages of the reaction and decreases with time until the end of the reaction. It can be found that the photocatalytic ability increases with an increase of film thickness. The photocatalytic efficiency at the reaction time of $60 \mathrm{~min}$ is $95 \%$, $99 \%$, and $99 \%$ for the films of $1 \mathrm{H}, 2 \mathrm{H}$, and $4 \mathrm{H}$, respectively.

3.2.2. Photocatalytic Kinetics. The kinetics of the degradation reaction is investigated by plotting the variations in $\mathrm{MB}$ concentration with time (Figure 6(b)). A linear section is obtained within the reaction time. The obtained values of the rate constant $\left(k^{\prime}\right)$ of the photocatalytic reactions are summarized in Table 1. The results reveal that the photocatalytic degradation of MB dye obeys the rule of the pseudo-first-order kinetic reaction. Moreover, the corresponding rate constants are $0.052,0.055$, and 0.068 per min with the increasing film thickness. Note that these radicals initially lead to the generation of free electrons and holes in the conduction and valence bands of the solid. They also lead to the formation of surface excited states that subsequently react with the surface molecules of the reagents and then accelerate the decomposition reaction rate as the film thickness of hematite films increases. The reason for a better photocatalytic ability of 


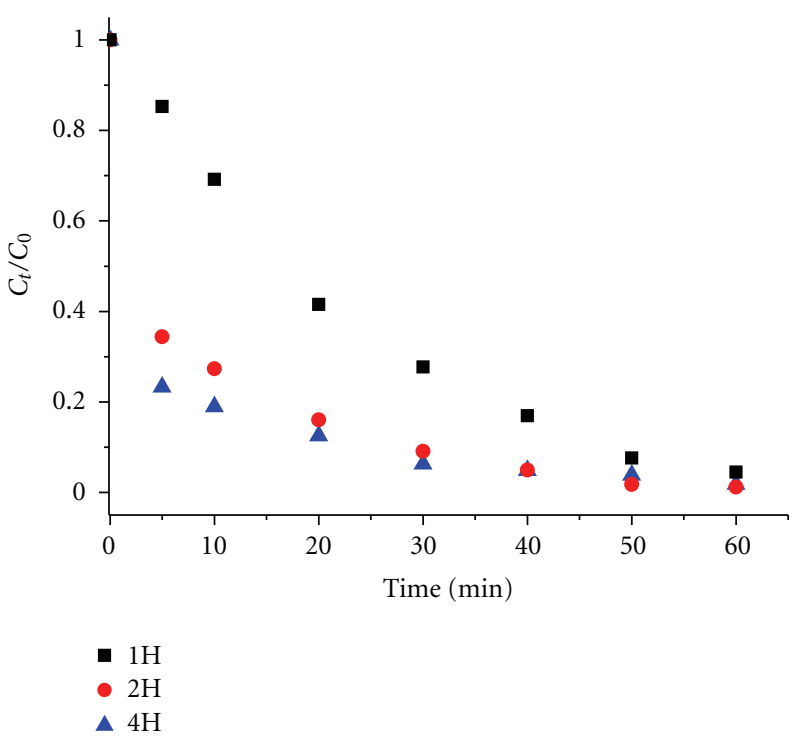

(a)

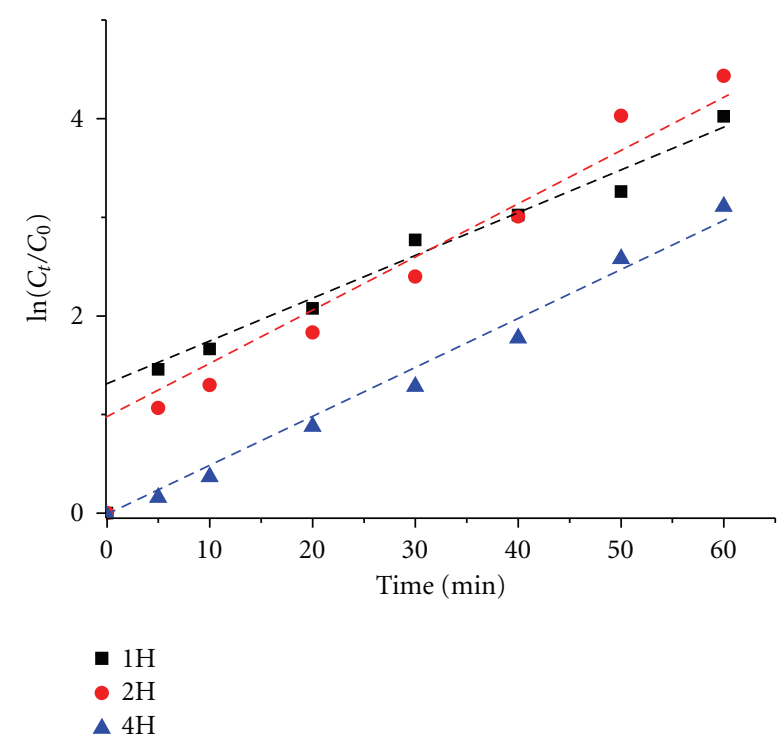

(b)

Figure 6: (a) Plot of photocatalytic efficiency versus the degradation time for the hematite films; (b) plot of log $C / C_{0}$ versus irradiation time for hematite films.

the hematite film with a thicker film thickness is a large surface roughness and a small band gap. A large surface roughness provides a large number of reaction sites for photocatalysis; a small band gap generates more electron-hole pairs under light irradiation. Consequently, a thicker hematite film has a better photocatalytic activity.

Previous studies have shown that the photocatalytic rates constant of the nanohematite and $\mathrm{Fe}_{2} \mathrm{O}_{3} / \mathrm{RR}\left(0.02 \mathrm{M} \mathrm{H}_{2} \mathrm{O}_{2}\right)$ are 0.0026 and $0.0029 \mathrm{~min}^{-1}$, respectively [26,27]. Moreover, the photocatalytic efficiency at the reaction time of $60 \mathrm{~min}$ for $\mathrm{Fe}_{2} \mathrm{O}_{3}$ thin film, $\mathrm{TiO}_{2} / \mathrm{Fe}_{2} \mathrm{O}_{3}$ thin film, $\alpha-\mathrm{Fe}_{2} \mathrm{O}_{3} / \mathrm{SnO}_{2}$ glass thin film, and $\mathrm{Fe}_{2} \mathrm{O}_{3}$ nanorod thin film is $30 \%, 15 \%$, $8 \%$, and $0.3 \%$ [28-30]. The detailed comparisons of photocatalysts are listed in Table 2, which indicates that the photocatalytic activity of hematite thin films is competitive with the reported literatures. Therefore, the hematite thin film can act as a good photocatalyst under visible-light excitations, and it is able to successfully utilize solar energy for performing photocatalysis.

\section{Conclusion}

In this study, it is observed that hematite thin films with different film thicknesses can be fabricated by the rf magnetron sputtering deposition. The FE-SEM images show that the grain size and the surface roughness increase with an increase in the film thickness. The band gap decreases with the increasing grain size (film thickness) because of the potential barrier at the grain boundary. The result of the photocatalytic degradation of $\mathrm{MB}$ reveals that all the films have a good photocatalytic ability; a thicker hematite film, with a larger grain size, has a better photocatalytic efficiency because of a smaller band bap and a rougher surface. We believe that with continued development, this type of thin film will have the potential to be employed in environmental remediation applications.

\section{Acknowledgment}

The authors would like to thank the National Science Council for the financial support.

\section{References}

[1] H. A. Mekkawy, M. O. Ali, and A. M. El-Zawahry, "Toxic effect of synthetic and natural food dyes on renal and hepatic functions in rats," Toxicology Letters, vol. 95, pp. 155-161, 1998.

[2] D. A. Oxspring, G. McMullan, W. F. Smyth, and R. Marchant, "Decolourisation and metabolism of the reactive textile dye, Remazol Black B, by an immobilized microbial consortium," Biotechnology Letters, vol. 18, no. 5, pp. 527-530, 1996.

[3] S. R. Couto, "Decolouration of industrial azo dyes by crude laccase from Trametes hirsuta," Journal of Hazardous Materials, vol. 148, no. 3, pp. 768-770, 2007.

[4] G. S. Nyanhongo, S. R. Couto, and G. M. Guebitz, "Coupling of 2,4,6-trinitrotoluene (TNT) metabolites onto humic monomers by a new laccase from Trametes modesta," Chemosphere, vol. 64, no. 3, pp. 359-370, 2006.

[5] B. Mishra, E. A. Haack, P. A. Maurice, and B. A. Bunker, "A spectroscopic study of the effects of a microbial siderophore on Pb adsorption to kaolinite," Chemical Geology, vol. 275, no. 3-4, pp. 199-207, 2010.

[6] J. Hu, I. M. C. Lo, and G. Chen, "Performance and mechanism of chromate (VI) adsorption by $\delta$-FeOOH-coated maghemite $\left(\gamma\right.$ - $\left.\mathrm{Fe}_{2} \mathrm{O}_{3}\right)$ nanoparticles," Separation and Purification Technology, vol. 58, no. 1, pp. 76-82, 2007.

[7] K. Yang, X. Wang, L. Zhu, and B. Xing, "Competitive sorption of pyrene, phenanthrene, and naphthalene on multiwalled carbon nanotubes," Environmental Science and Technology, vol. 40, no. 18 , pp. 5804-5810, 2006.

[8] A. W. M. Ip, J. P. Barford, and G. McKay, "Production and comparison of high surface area bamboo derived active carbons," Bioresource Technology, vol. 99, no. 18, pp. 8909-8916, 2008 . 
[9] A. E. Nemr, O. Abdelwahab, A. El-Sikaily, and A. Khaled, "Removal of direct blue- 86 from aqueous solution by new activated carbon developed from orange peel," Journal of Hazardous Materials, vol. 161, no. 1, pp. 102-110, 2009.

[10] S. Ahuja and T. R. N. Kutty, "Nanoparticles of $\mathrm{SrTiO}_{3}$ prepared by gel to crystallite conversion and their photocatalytic activity in the mineralization of phenol," Journal of Photochemistry and Photobiology A, vol. 97, no. 1-2, pp. 99-107, 1996.

[11] D. L. Liao and B. Q. Liao, "Shape, size and photocatalytic activity control of $\mathrm{TiO}_{2}$ nanoparticles with surfactants," Journal of Photochemistry and Photobiology A, vol. 187, no. 2-3, pp. 363369, 2007.

[12] S. Vaidyanathan, K. R. Ryan, and E. W. Eduardo, "Synthesis and UV-visible-light photoactivity of noble-metal-SrTiO composites," Industrial and Engineering Chemistry Research, vol. 45, no. 7, pp. 2187-2193, 2006.

[13] Y. Zhang, J. C. Crittenden, D. W. Hand, and D. L. Perram, "Fixed-bed photocatalysts for solar decontamination of water," Environmental Science and Technology, vol. 28, no. 3, pp. 435-442, 1994.

[14] L. Chang, J. B. Liu, J. S. Wang, and W. X. Zhang, "Synthesis and photocatalytic activity of visible-light-sensitive Fe doped $\mathrm{TiO}_{2}$ hollow microspheres," Chinese Journal of Inorganic Chemistry, vol. 26, no. 5, pp. 744-748, 2010.

[15] J. Wang, Z. Wang, H. Li, Y. Cui, and Y. Du, "Visible lightdriven nitrogen doped $\mathrm{TiO}_{2}$ nanoarray films: preparation and photocatalytic activity," Journal of Alloys and Compounds, vol. 494, no. 1-2, pp. 372-377, 2010.

[16] T. Takei, R. Haramoto, Q. Dong et al., "Photocatalytic activities of various pentavalent bismuthates under visible light irradiation," Journal of Solid State Chemistry, vol. 184, no. 8, pp. 2017-2022, 2011.

[17] Y. Yang, Q. Wu, Y. Guo, C. Hu, and E. Wang, "Efficient degradation of dye pollutants on nanoporous polyoxotungstateanatase composite under visible-light irradiation," Journal of Molecular Catalysis A, vol. 225, no. 2, pp. 203-212, 2005.

[18] M. H. Priya and G. Madras, "Kinetics of photocatalytic degradation of phenols with multiple substituent groups," Journal of Photochemistry and Photobiology A, vol. 179, no. 3, pp. 256262, 2006.

[19] S. Jacob, T. Roch, F. S. Razavi, G. M. Gross, and H. U. Habermeier, "The thickness dependence of the effect of pressures on magnetic and electronic properties of thin films of $\mathrm{La}_{2 / 3}$ $\mathrm{Ca}_{1 / 3} \mathrm{MnO}_{3}$," Journal of Applied Physics, vol. 91, no. 4, pp. 2232-2235, 2002.

[20] J. Islam, Y. Yamamoto, and H. Hori, "Thickness-dependent coercivity and magnetization process of Co/GaAs (100)," Journal of Magnetism and Magnetic Materials, vol. 310, no. 2, pp. 2234-2236, 2007.

[21] R. N. Goyal, D. Kaur, and A. K. Pandey, "Growth and characterization of iron oxide nanocrystalline thin films via low-cost ultrasonic spray pyrolysis," Materials Chemistry and Physics, vol. 116, no. 2-3, pp. 638-644, 2009.

[22] D. Bao, X. Yao, N. Wakiya, K. Shinozaki, and N. Mizutani, "Band-gap energies of sol-gel-derived $\mathrm{SrTiO}_{3}$ thin films," Applied Physics Letters, vol. 79, no. 23, pp. 3767-3769, 2001.

[23] E. L. Miller, D. Paluselli, B. Marsen, and R. E. Rocheleau, "Low-temperature reactively sputtered iron oxide for thin film devices," Thin Solid Films, vol. 466, no. 1-2, pp. 307-313, 2004.

[24] H. S. Lee, C. S. Woo, B. K. Youn et al., "Bandgap modulation of $\mathrm{TiO}_{2}$ and its effect on the activity in photocatalytic oxidation of 2-isopropyl-6-methyl-4-pyrimidinol," Topics in Catalysis, vol. 35 , no. 3-4, pp. 255-260, 2005.
[25] A. U. Ubale, D. M. Choudhari, J. S. Kantale et al., "Synthesis of nanostructured $\mathrm{Cu}_{x} \mathrm{~S}$ thin films by chemical route at room temperature and investigation of their size dependent physical properties," Journal of Alloys and Compounds, vol. 509, no. 37, pp. 9249-9254, 2011.

[26] M. H. Khedr, K. S. Abdel Halim, and N. K. Soliman, "Synthesis and photocatalytic activity of nano-sized iron oxides," Materials Letters, vol. 63, no. 6-7, pp. 598-601, 2009.

[27] J. Bandara, U. Klehm, and J. Kiwi, "Raschig rings- $\mathrm{Fe}_{2} \mathrm{O}_{3}$ composite photocatalyst activate in the degradation of 4-chlorophenol and Orange II under daylight irradiation," Applied Catalysis B, vol. 76, no. 1-2, pp. 73-81, 2007.

[28] E. Sánchez Mora, E. Gómez Barojas, E. R. Rojas, and R. Silva González, "Morphological, optical and photocatalytic properties of $\mathrm{TiO}_{2}-\mathrm{Fe}_{2} \mathrm{O}_{3}$ multilayers," Solar Energy Materials and Solar Cells, vol. 91, no. 15-16, pp. 1412-1415, 2007.

[29] T. Kawahara, K. I. Yamada, and H. Tada, "Visible light photocatalytic decomposition of 2-naphthol by anodic-biased $\alpha$ $\mathrm{Fe}_{2} \mathrm{O}_{3}$ film," Journal of Colloid and Interface Science, vol. 294, no. 2, pp. 504-507, 2006.

[30] H. G. Cha, C. W. Kim, Y. H. Kim et al., "Preparation and characterization of $\alpha-\mathrm{Fe}_{2} \mathrm{O}_{3}$ nanorod-thin film by metal-organic chemical vapor deposition," Thin Solid Films, vol. 517, no. 5, pp. 1853-1856, 2009. 


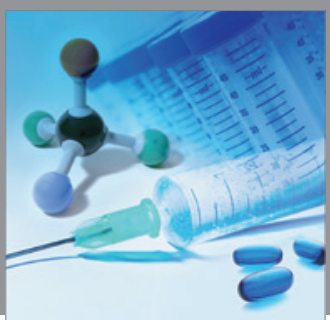

International Journal of

Medicinal Chemistry

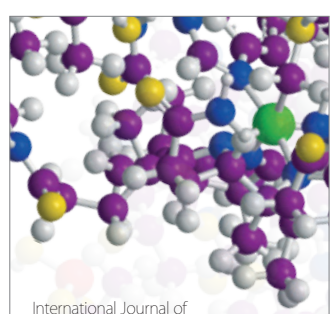

Carbohydrate Chemistry

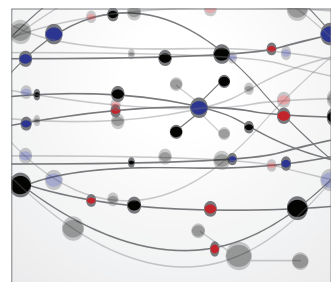

The Scientific World Journal
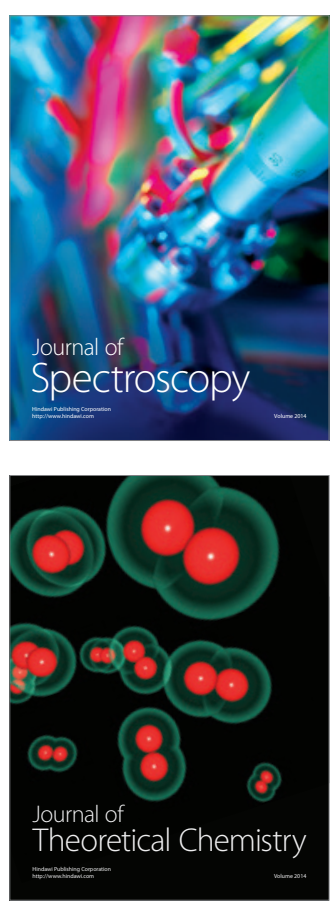
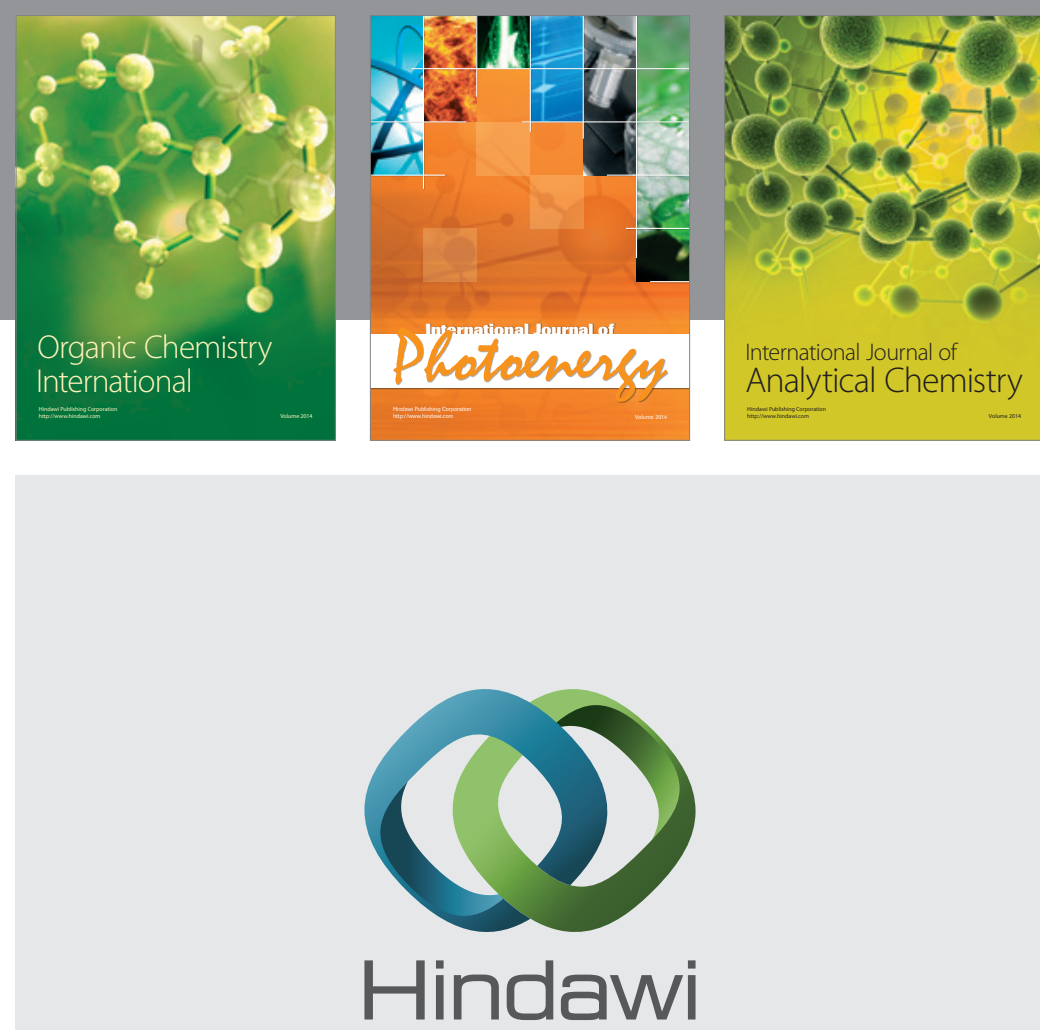

Submit your manuscripts at

http://www.hindawi.com
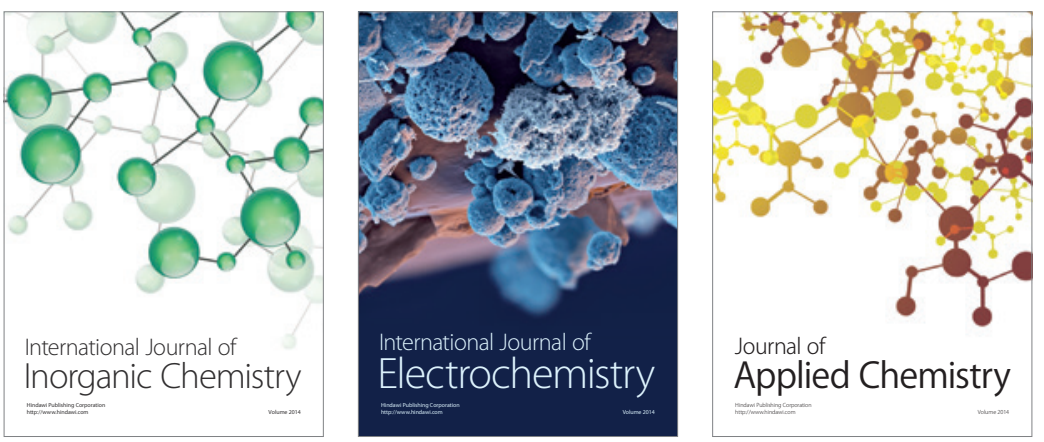

Journal of

Applied Chemistry
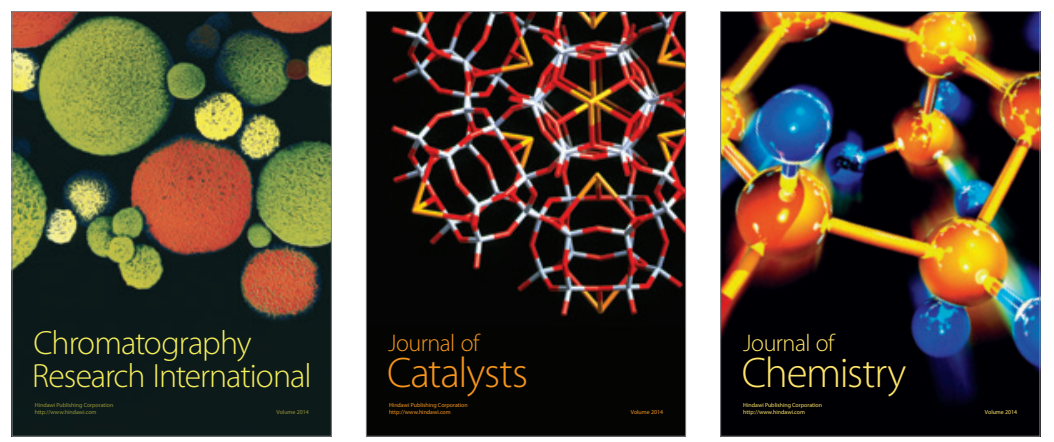
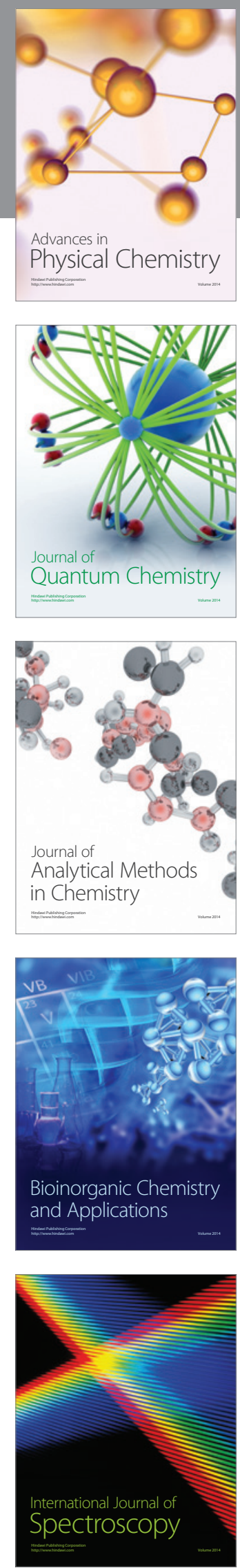